Tropical Journal of Pharmaceutical Research December 2016; 15 (12): 2683-2692

ISSN: $1596-5996$ (print); 1596-9827 (electronic)

(C) Pharmacotherapy Group, Faculty of Pharmacy, University of Benin, Benin City, 300001 Nigeria.

All rights reserved.

Available online at http://www.tjpr.org

Original Research Article

http://dx.doi.org/10.4314/tjpr.v15i12.21

\title{
Liquid chromatographic-tandem mass spectrometric assay for simultaneous quantitation of tofacitinib, cabozantinib and afatinib in human plasma and urine
}

\author{
Adnan A Kadi ${ }^{1}$, Ali S Abdelhameed ${ }^{1 \star}$, Hany W Darwish ${ }^{1,2}$, Mohamed W Attwa ${ }^{1}$ \\ and Ahmed $\mathrm{H}$ Bakheit ${ }^{1}$ \\ ${ }_{1}^{1}$ Department of Pharmaceutical Chemistry, College of Pharmacy, King Saud University, PO Box 2457 Riyadh, 11451, Kingdom \\ of Saudi Arabia, ${ }^{2}$ Analytical Chemistry Department, Faculty of Pharmacy, Cairo University, Kasr El-Aini St, Cairo 11562, Egypt \\ ${ }^{*}$ For correspondence: Email: asaber@ksu.edu.sa; Fax: +966114676220
}

Revised accepted: 12 November 2016

\begin{abstract}
Purpose: To develop a simple, adequately sensitive, and practical liquid chromatographic-mass spectrometric method to simultaneously quantify three tyrosine kinase inhibitors, viz, tofacitinib (TOF), cabozantinib (CBZ) and afatinib (AFB) after their extraction from both human plasma and urine.

Methods: Blood and urine samples were obtained from healthy volunteers who admitted to not being on any medications. The investigated analytes were chromatographically separated on a C18 column (Luna®-PFP $100 \AA$ column, $50 \mathrm{~mm} \times 2.0 \mathrm{~mm}$ i.d., $3.0 \mu \mathrm{m}$ ) with the aid of a mobile phase containing $A$; acetonitrile $(A C N)$ and $B ; 0.01 \mathrm{M}$ ammonium formate buffer $\left(\mathrm{pH}\right.$ 4.1) pumped at a rate of $0.3 \mathrm{~mL}^{\mathrm{min}} \mathrm{m}^{-1}$ in the ratio $A: B, 50: 50 \mathrm{v} / \mathrm{v}$. Analyte monitoring was achieved by tandem mass spectrometry interfaced with an electrospray ionization source with the aid of multiple reaction monitoring (MRM) mode for analytes quantification.

Results: The proposed method permitted a specific and sensitive determination of the investigated TKls in the linear range of 1.0 - $100 \mathrm{ng} \mathrm{mL-1}$ with correlation coefficient $\left(r^{2}\right)$ of $0.9991,0.9997$, and 0.9998 for TOF, CBZ and AFB, respectively. The method was validated with regard to its limits of quantification (ranging from 0.91 to $1.24 \mathrm{ng} \mathrm{mL-1}$ for the 3 analytes), intra- and inter assay accuracy (in the range -1.85 to $1.22 \%)$ and precision (0.71 - $5.12 \%)$. The method was also validated in terms of recovery from both studied matrices, robustness and matrix effect.

Conclusion: The results obtained reveal that the developed method is simple, specific and highly efficient for routine determination of the studied analytes in human plasma and urine. It can be reliably applied for high throughput analysis of clinical samples containing the investigated analytes.
\end{abstract}

Keywords: Tyrosine kinase inhibitors, Tofacitinib, Cabozantinib, Afatinib, LC-MS/MS, human plasma

Tropical Journal of Pharmaceutical Research is indexed by Science Citation Index (SciSearch), Scopus, International Pharmaceutical Abstract, Chemical Abstracts, Embase, Index Copernicus, EBSCO, African Index Medicus, JournalSeek, Journal Citation Reports/Science Edition, Directory of Open Access Journals (DOAJ), African Journal Online, Bioline International, Open-J-Gate and Pharmacy Abstracts

\section{INTRODUCTION}

Tyrosine kinases (TKs) are deemed potential targets for new drug development, especially for cancer and rheumatoid arthritis drugs. Over the last decade, several tyrosine kinase inhibitors (TKIs) have been developed and approved for the treatment of various types of cancer, with each of them targeting specific signaling pathways [1,2]. Furthermore, more recent advances have also led to the discovery of the Janus kinases (JAKs) [3], which by their inhibition introduced new therapeutic approach for cancer and immunity disorders [4]. 
In the current study a simple analytical procedure was designed to be able to simultaneously quantify various TKIs in human plasma, hence, three FDA approved medications were selected as representative examples of the TKIs acting on the different kinases. Firstly, afatinib (AFB; Fig 1a), a selective TKI that blocks the signaling pathways from the receptor tyrosine kinases HER1 (EGFR/ErbB1), HER2 (ErbB2), and HER4 (ErbB4) [5]. In 2013, the U.S. FDA approved the drug to be used with patients suffering of locally advanced or metastatic non-small cell lung cancer (NSCLC) with their tumors showing EGFR (epidermal growth factor receptor) mutations either as deletions of exon 19 or substitution of exon 21 [6].

The second chosen TKI representative is cabozantinib (CBZ; Fig. 1b)), which is also an orally active agent that blocks the activity of different tyrosine kinases including mesenchymal-epithelial transition factor (MET) and vascular endothelial growth factor receptor types 1 (VEGFR-1), 2 (VEGFR-2), and 3 (VEGFR-3) [7]. In 2011, the U.S. FDA approved CBZ for the management of patients with progressive, metastatic medullary thyroid cancer; in 2015 it was also approved by the European Medicines Agency (EMA) for the same use. The last chosen kinase inhibitor is tofacitinib (TOF; Figure 1c), which is a representative of the Janus kinase inhibitors (JAKIs). TOF is reported to selectively block the signaling pathway involving the kinases JAK 1 and 3 [8]. TOF was approved by the U.S. FDA in 2012 for the management of patients with moderate to severe rheumatoid arthritis (RA) either alone or to be taken with methotrexate in more sever un-responsive cases [9].

Screening of the literature disclosed few published reports for the quantification of $A F B$, $\mathrm{CBZ}$, and TOF either alone or in combination with other medications. Determination of AFB alone was reported in two recent studies in human plasma using UPLC-DAD [10], LC-MS [11], with two other liquid chromatographic procedures published for its quantitation in tablets [12,13]. Moreover, one recent study reported AFB simultaneous determination with other TKIs namely, vandetanib, pazopanib, and dasatinib in human plasma using HPLC-DAD [14] with the AFB linearity range $0.7-7.0 \mu \mathrm{gmL}^{-1}$, which is higher than its reported $\mathrm{C}_{\max }$ (maximum plasma concentration) value of 6.19 - $7.58 \mathrm{ngmL}^{-}$ [11] and 11.6 - $40.8 \mathrm{ngmL}^{-1}$ after administration of single and multiple doses of different AFB concentrations [15]. On the other hand, individual CBZ quantification was reported using HPLC-UV [16], LC-MS/MS $[17,18]$ in rat plasma with one study using micellar enhanced spectrofluorimetry in human plamsa [19].

The reported $\mathrm{C}_{\max }$ of $\mathrm{CBZ}$-depends mostly on its dose, which was in the range of $34.2-603 \mathrm{ngmL}^{-1}$ after oral administration of $0.08 \mathrm{mgkg}^{-1}$ to 1.28 $\mathrm{mgkg}^{-1}$. Ultimately, with its lowest reported observed plasma concentration $~ 81 \mathrm{ngmL}^{-1}$ [20], quantitative determination of TOF alone was reported using HPLC-UV in rat plasma [21], for its enantiomers separation [22], using LC-MS alone [23], and in combination with methotrexate in rat plasma [24].

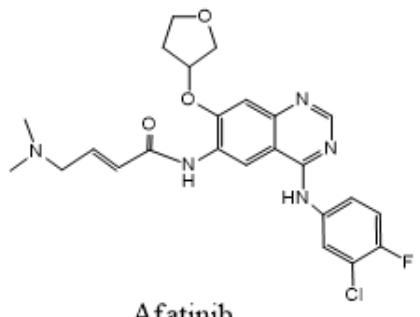

Afatinib

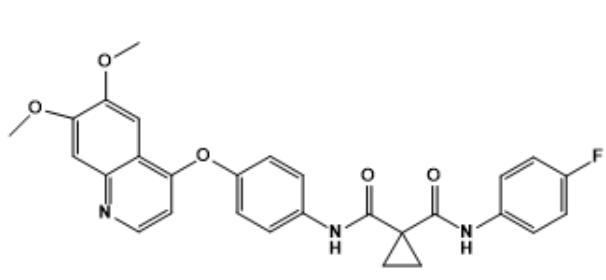

Cabozantinib

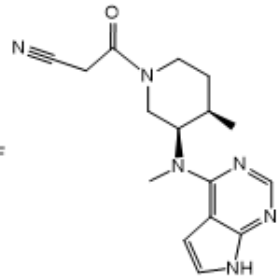

Tofacitinib

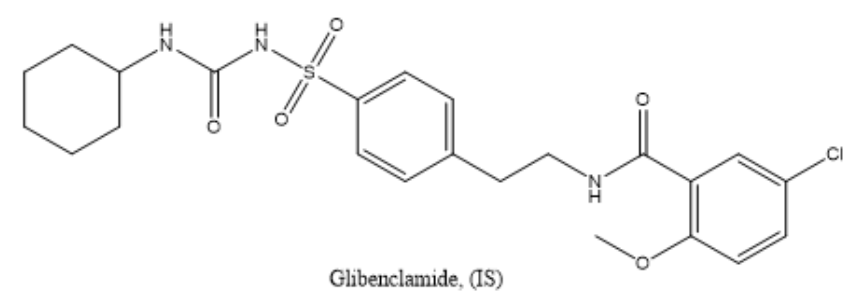

Figure 1: Chemical structures of the studied TKIs and IS. (Major errors in the structures of afatinib and tofacitinib; indicate "glibenclamide" as "glibenclamide (IS)") 
Hence, to date no study has been published for the determination of AFB, CBZ, and TOF although, as per clinical decisions, TOF as an anti-rheumatoid arthritis therapy may be administered with AFB or CBZ or any other TKI in patients suffering both diseases. This study is therefore conducted to establish and comprehensively validate a new LC-MS/MS method to simultaneously quantify AFB, CBZ, and TOF in human plasma under their plasma concentration levels.

\section{EXPERIMENTAL}

\section{Chemicals and reagents}

Reference standards of AFB, CBZ, and TOF of $>$ $99 \%$ purity were acquired from Weihua Pharma Co. Ltd (Zhejiang, China). Ultrapure solvents and reagents of HPLC-grade were obtained from Merck BDH Ltd. (Poole, U.K). Blood samples were obtained from King Khaled University Hospital (King Saud University, Riyadh, KSA), following informed consent was acquired, fasting blood specimen were collected, plasma was then separated and stored frozen at $-70{ }^{\circ} \mathrm{C}$. Human urine was obtained from healthy male volunteers who admitted to not being on any medications. The ethics review committee of the College of Pharmacy, King Saud University, Riyadh, Saudi Arabia approved the study protocol (approval no. 14370511), which followed the international ethical guidelines for biomedical research involving human subjects [25]. A Milli-Q plus water purification system (Merck Millipore, MA, USA) was used to produce ultra-pure water $\geq$ 18.2 $\mathrm{M} \Omega$ that was used throughout the study.

\section{Instrumentation and conditions}

Chromatographic resolution of the analytes was executed through an Agilent 1200 HPLC system with their quantitative determination carried out using an Agilent 6410 triple quadrupole (Agilent Technologies, CA, USA). Analytes chromatographic elution was accomplished utilizing a mobile phase containing solvents $A$;
Acetonitrile (ACN) and $\mathrm{B}$; $0.01 \mathrm{M}$ ammonium formate buffer ( $\mathrm{pH}$ 4.1) pumped binarily at 0.3 $\mathrm{mLmin}^{-1}$ in the ratio $\mathrm{A}: \mathrm{B}, 50: 50 \mathrm{v} / \mathrm{v}$. A C18 column (Luna®-PFP 100A column) (50 mm x 2.0 $\mathrm{mm}$ i.d., $3.0 \mu \mathrm{m})$ (Phenomenex Inc., CA, USA) was used for the analytes separation at ambient temperature. Following their elution, analytes were sprayed into the mass spectrometer using an ESI (electrospray ionization) interface running in the positive ionization mode with the ESI temperature set to $350{ }^{\circ} \mathrm{C}$. Low and high purity nitrogen gas were used as desolvation gas flowing at $12 \mathrm{Lmin}^{-1}$ and neubilizer gas with a pressure of 55 psi, respectively. Capillary voltage was set to $4 \mathrm{kV}$ and a Dwell time of $200 \mathrm{~ms}$ was maintained, for all ions. All separation and detection parameters were adjusted to augment the chromatographic resolution and mass spectrometric response. The optimized MS parameters for individual parent and daughter ions are listed in Table 1. A MassHunter software (Agilent Technologies, CA, USA) was used throughout the study to control the LC-MS system and to acquire the data.

\section{Preparation of standard solutions}

AFB, CBZ, TOF, and IS Standard solutions of $200 \mu \mathrm{g} \mathrm{mL}-1$ were freshly prepared in methanol at room temperature. Further dilutions were carried out using methanol to achieve $10 \mu \mathrm{g} \mathrm{mL}$ 1 working solutions. Further dilutions of each analyte were attained in mobile phase to prepare calibration and quality control (QC) samples.

\section{Calibration curves samples for plasma and urine}

Calibration curves were constructed in both spiked drug-free human plasma and urine with $\mathrm{AFB}, \mathrm{CBZ}$, and TOF concentrations in the concentration range $1.0-100 \mathrm{ng} \mathrm{mL}^{-1}$. Aliquots of $100 \mu \mathrm{L}$ of $\mathrm{AFB}, \mathrm{CBZ}$, and TOF were spiked into $1 \mathrm{~mL}$ of human plasma/urine and appropriate volumes were then mixed with $350 \mu \mathrm{L}$ of $0.1 \mathrm{M}$ glycine buffer ( $\mathrm{pH} \sim 9.0)$.

Table 1: MS optimized parameters of the investigated analytes

\begin{tabular}{lccccc}
\hline Analyte & $\begin{array}{c}\text { Parent Ion } \\
(\mathbf{m} / \mathbf{z})\end{array}$ & $\begin{array}{c}\text { Fragment Ion } \\
(\mathbf{m} / \mathbf{z})\end{array}$ & $\begin{array}{c}\text { Fragmentor voltage } \\
(\mathbf{V})\end{array}$ & $\begin{array}{c}\text { Collision } \\
\text { energy }(\mathbf{e V})\end{array}$ & $\begin{array}{c}\text { Time segment for } \\
\text { MRM scan }(\mathbf{m i n})\end{array}$ \\
\hline TOF & 313.2 & 165.0 & 135 & 20 & $0.0-1.3$ \\
& 313.2 & 148.9 & 135 & 20 & $0.0-1.3$ \\
AFB & 486.1 & 371.0 & 140 & 30 & $1.3-2.0$ \\
& 486.1 & 305.0 & 145 & 34 & $1.3-2.0$ \\
IS & 494.0 & 369.0 & 135 & 15 & $2.0-2.8$ \\
& 494.0 & 168.9 & 135 & 15 & $2.0-2.8$ \\
CBZ & 502.2 & 391.1 & 135 & 32 & $2.8-4.0$ \\
& 502.2 & 323.1 & 135 & 34 & $2.8-4.0$ \\
\hline
\end{tabular}


A volume of $50 \mu \mathrm{L}$ of IS (200 ng mL $\mathrm{m}^{-1}$ ) was added and subsequent liquid-liquid extraction was performed to those samples via the addition of diethyl ether (4 $\mathrm{mL})$ succeeded by separation and evaporation of the organic phase under a gentle stream of nitrogen. Residues were reconstituted in mobile phase and filtered through a $0.45 \mu \mathrm{m}$ Millex filter (Millipore, MA, USA). Additionally, three quality control samples of 7.0,50, and $80 \mathrm{ng} \mathrm{mL}^{-1}$ and three solutions for incurred sample reanalysis (ISR) with concentrations of 10,50 , and $100 \mathrm{ng} \mathrm{mL}^{-1}$ were prepared in human plasma only. Blank plasma/urine samples were similarly treated with ultrapure water replacing the analytes solutions.

\section{Calibration curve construction}

Three calibration graphs of each analyte in both plasma and urine, were executed by plotting peak area ratio of each analyte to IS against the corresponding analyte concentrations using $1 / \mathrm{X}^{2}$ as a weighing factor. Calibrator response functions and choice of regression analysis were chosen by evaluating the percentage relative error (\% RE) for all calibrators as described by Almeida et al [26].

\section{Method validation}

\section{Specificity}

The method specificity was investigated via the analysis of 6 blank plasma/urine samples processed according the proposed procedure. The injected samples were subsequently examined for any elution interference compared to the analytes samples either in plasma or urine.

\section{Linearity and sensitivity}

Three different calibration graphs were plotted for plasma and urine samples, and were used to determine the method's linearity and sensitivity. Limit of detection (LOD) and lower limit of quantification (LLOQ) were estimated via equation 1 , using the calibration curve slope (b) and standard deviation of the intercept (SD0).

$\mathrm{LLOQ}$ or $\mathrm{LOD}=\mathrm{kSD} / \mathrm{b}$

where $k$ is 10 for LLOQ and 3.3 for LOD

\section{Precision and accuracy}

Intra- and inter-day assessments of both accuracy and precision were performed through the analysis of the QC samples 3 times in a single day and over 3 consecutive days, respectively. The coefficient of variation percent
(\%CV) was used as an indication of precision and was calculated as per equation 2 using the calculated mean and standard deviation values of each sample determination.

$(\% \mathrm{CV})=[\mathrm{SD} / \mathrm{M}] \times 100$

where $\mathrm{M}$ is the mean measured concentration. Percent error (\% error) was used to refer to the accuracy of those samples determinations and computed following equation 3 .

$\%$ Error $=[(\mathrm{M}-\mathrm{N}) / \mathrm{N}] \times 100$

where $\mathrm{N}$ is the nominal concentration.

Furthermore, the 3 ISR samples were assessed and their mean concentrations were calculated and set as initial values (I), a week later those samples were reanalyze yielding their "repeat values". The difference (\% D) in ISR samples was then computed as in equation 4.

$\% D=[(I-R) / V] \times 100$

where $\mathrm{V}$ is the mean of initial and repeat values of each sample.

\section{Recovery and matrix effect}

Analytes recovery was determined in both matrices to infer the extraction efficiency of the current procedure. Recoveries were evaluated by comparing the mean peak area ratio of each analyte to IS in the extracted QC samples to those extracted from blank plasma and urine, which were exposed to post-spiking with the respective reference solutions.

For calculation of absence of matrix effect (\% A) for both matrices, Eq 3 was used.

$\% A=(B / C) \times 100$

where $\mathrm{B}$ and $\mathrm{C}$ are the mean peak area ratio of plasma/urine samples and aqueous samples, respectively.

\section{Robustness}

Robustness of the proposed analytical procedure was investigated by examining the influence of individual modifications/changes within the analytical settings around the proposed optimum value in the current procedure. Those intervaried parameters reflect probable alterations occurring in diverse test environments. The modified mobile phase parameters were the composition ratio of $\mathrm{A}$ and $\mathrm{B}$, flow rate, and $\mathrm{pH}$ of solvent $B$. 


\section{RESULTS}

MRM chromatograms representing plasma samples of the analytes under the aforementioned chromatographic and mass spectrometric conditions are shown in Figure 2.

\section{Validation results}

\section{Specificity}

Figure 3 demonstrates the MS spectra produced during the product ion $\left(\mathrm{MS}^{2}\right)$ and MRM scans of the investigated TKIs. Hence, the current method was proved specific with the absence of interfering signals in blank plasma samples within the elution time period of the analytes.

\section{Linearity and sensitivity}

Calibration curves in both plasma and urine samples of the studied TKIs provided linear relationships with low standard deviations for all calibration. Table 2 summarizes the different analytical parameters including the LOD and LLOQ, which were computed to be below the

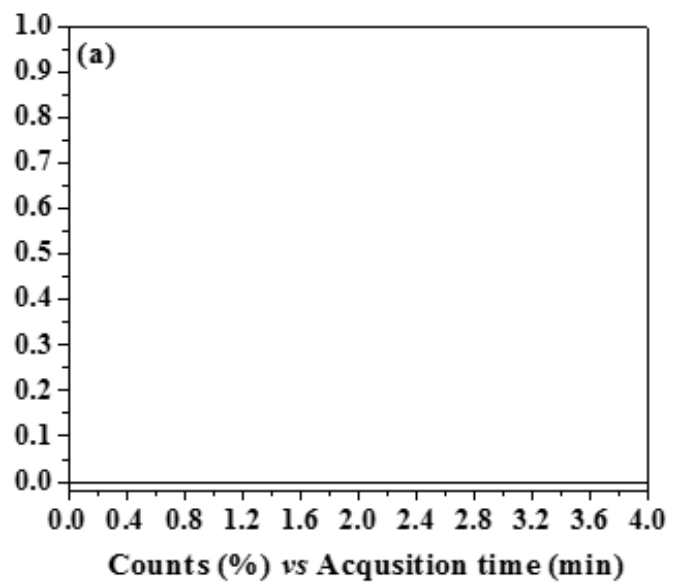

reported $C_{\max }$ values $[15,20,27]$ of the studied TKIs.

\section{Precision and accuracy}

Accuracy and precision of the present method were evaluated on intra- and inter- day basis as previously described, the results listed in Table 3 proved the method's efficiency with the demonstrated low $\mathrm{CV} \%$ and RE. In a similar vein, 3 concentrations of 10,50 , and $100 \mathrm{ng} \mathrm{mL}^{-1}$ of the studied TKIs in spiked human plasma were assayed for incurred sample re-analysis and Table 4 clearly shows that their results confirmed the current method reproducibility.

\section{Effect of different matrices on analyte recovery}

Recovery data of the investigated TKls were computed and are listed in Table 5. Moreover, and for further confirmation of the absence of any matrix effect, two groups of three samples of blank plasma and urine were extracted and then spiked with the lowest QC concentration of the

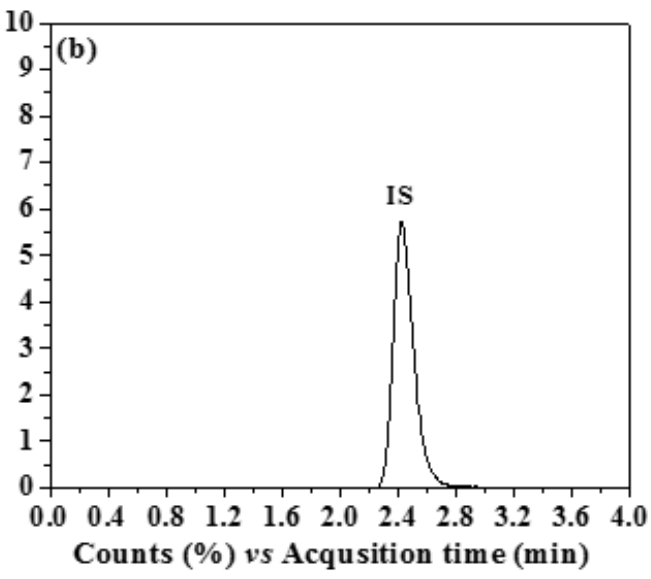

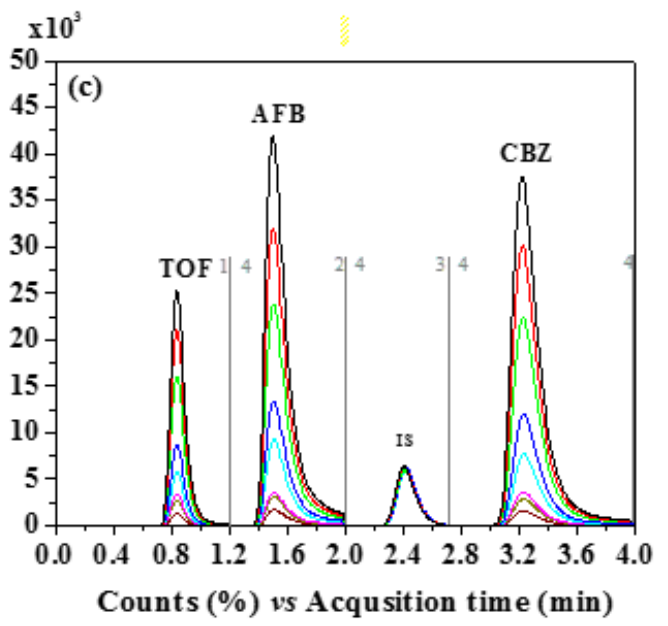

Figure 2: MRM chromatograms of a) double blank human plasma (without analytes and IS); b) blank human plasma with IS; c) Overlaid MRM chromatograms of TOF, AFB, IS, and CBZ in spiked human plasma samples 

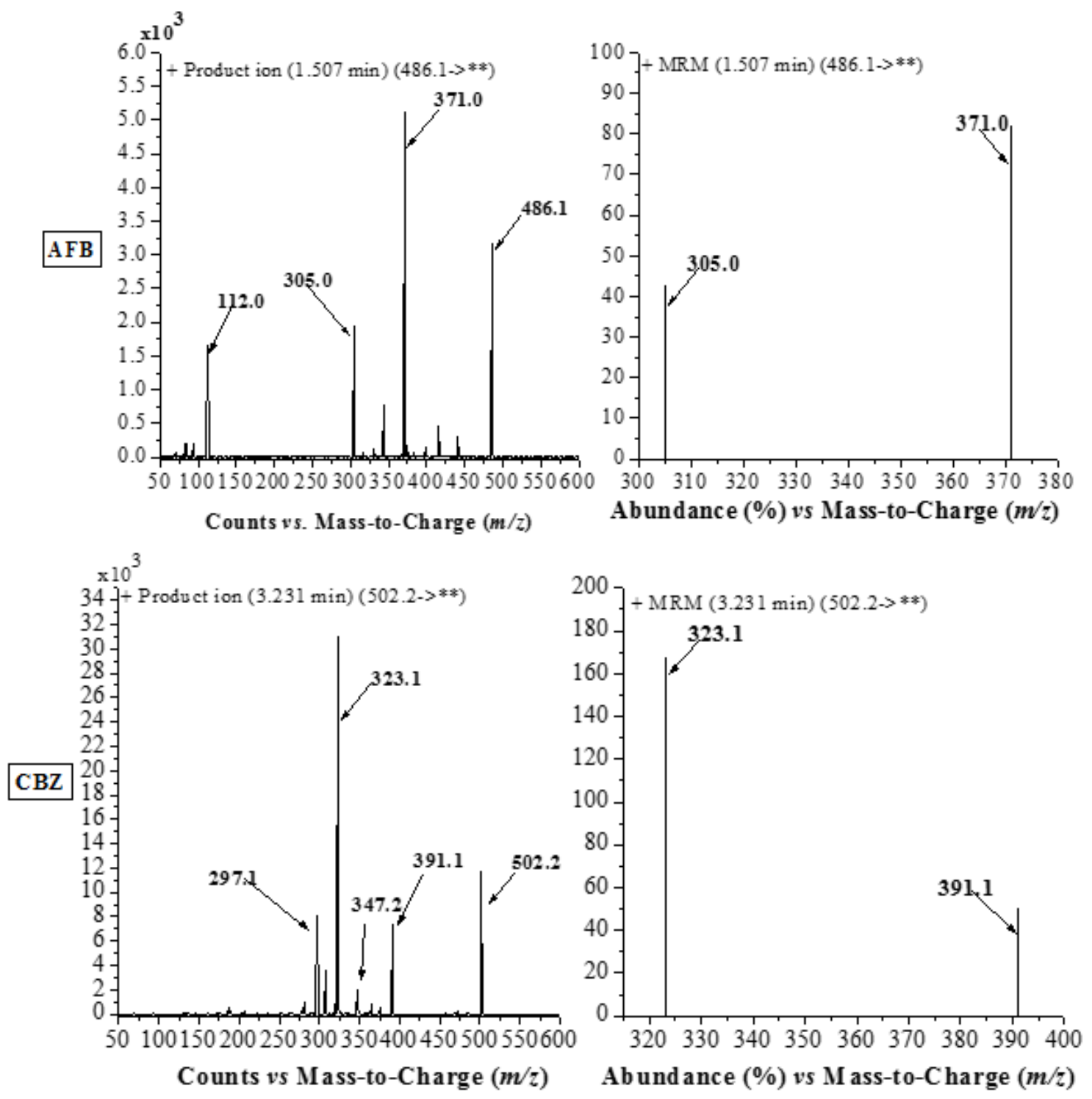

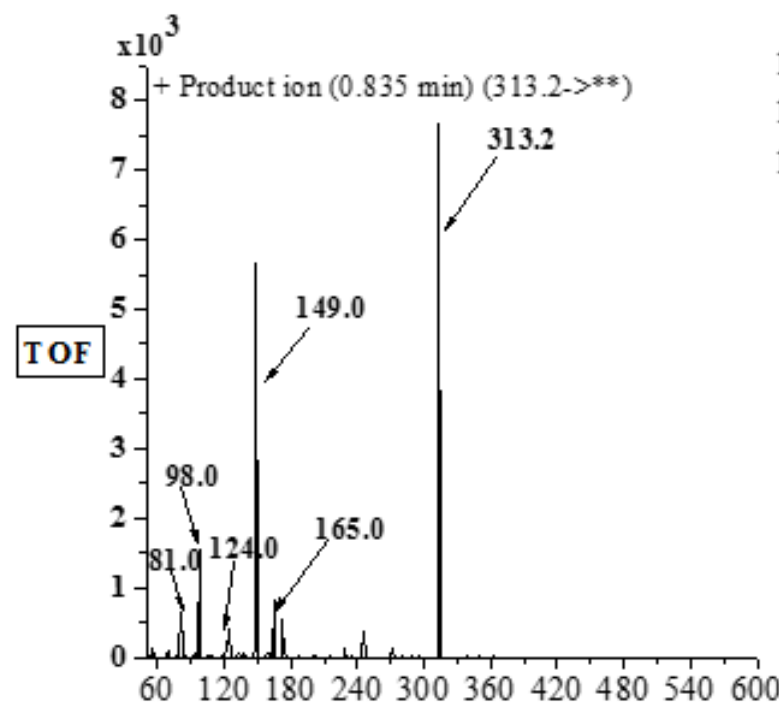

Counts vs Mass-to-Charge $(\mathrm{m} / \mathrm{z})$

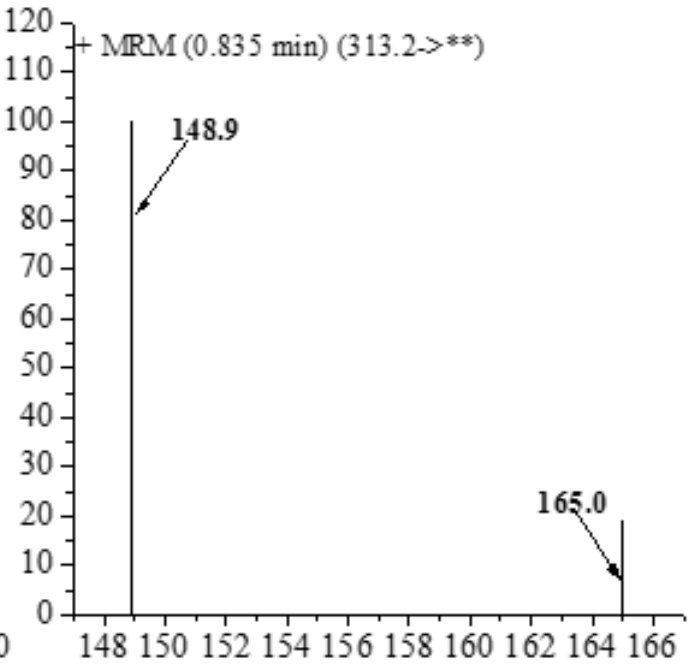

Abundance (\%) vs Mass-to-Charge ( $\mathrm{m} / \mathrm{z})$

Figure 3: $\mathrm{MS}^{2}$ and MRM spectra of TOF, AFB, and CBZ. 
analytes (i.e. $7.0 \mathrm{ng} \mathrm{mL}^{-1}$ ) and the IS. Concomitantly, another group with three samples of the same concentration and IS in aqueous solution (i.e. in mobile phase) was prepared. The different sample groups were analyzed and the absence of matrix effect percent was evaluated and listed in Table 5.

Table 2: Analytical parameters of the current analytical procedure

\begin{tabular}{|c|c|c|c|}
\hline Parameter & TOF & CBZ & AFB \\
\hline $\begin{array}{l}\text { Retention } \\
\text { time (min) }\end{array}$ & 0.835 & 3.231 & 1.507 \\
\hline $\begin{array}{l}\text { Linearity } \\
\left(\mathrm{ng} \mathrm{mL}^{-1}\right)\end{array}$ & $1.0-100$ & $1.0-100$ & $1.0-100$ \\
\hline $\begin{array}{l}\text { Intercept } \\
\pm S D\end{array}$ & $1.98 \pm 0.06$ & $2.87 \pm 0.09$ & $2.88 \pm 0.14$ \\
\hline Slope $\pm S D$ & $0.49 \pm 0.01$ & $1.08 \pm 0.02$ & $1.33 \pm 0.01$ \\
\hline $\begin{array}{l}\mathrm{LOD} \quad \text { (ng } \\
\left.\mathrm{mL}^{-1}\right)\end{array}$ & 0.41 & 0.29 & 0.34 \\
\hline $\begin{array}{l}\text { LLOQ } \quad \text { (ng } \\
\mathrm{mL}^{-1} \text { ) }\end{array}$ & 1.24 & 0.91 & 1.05 \\
\hline $\begin{array}{l}\text { Correlation } \\
\text { coefficient } \\
\left(R^{2}\right)\end{array}$ & 0.9991 & 0.9997 & 0.9998 \\
\hline
\end{tabular}

\section{Robustness}

Robustness was expressed by the relative standard deviation of the recovery results obtained from triplicate analysis of the studied TKIs in spiked human plasma with the intervaried analytical parameters. Table 6 demonstrates the current method robustness showing the results acquired following the modification of the investigated parameters from their optimum values according to the current analytical procedure.

\section{DISCUSSION}

Preliminary chromatographic and mass spectrometric optimizations were carried out in terms of mobile phase composition, flow rate, $\mathrm{pH}$ of the mobile phase, MRM transitions, etc. Subsequently, a mobile phase composed of ACN (A) and $0.01 \mathrm{M}$ ammonium formate in water $(\mathrm{pH}$ $\sim 4$.1) (B) $(A: B, 50: 50, v / v)$ was chosen for analytes separation and elution at a flow rate of $0.3 \mathrm{mLmin}^{-1}$. The use of MRM scanning protocol has enhanced the quantitative sensitivity of the method and eliminated any interference arising from the effects of the different matrices during the analytes elution. Following method development, the proposed method was validated according to the International Conference on Harmonisation (ICH) $[56,57]$ and the U.S. Food and Drug Administration (FDA) guidance [58]. Validation was conducted with regard to specificity, linearity, sensitivity, intra- and inter-day accuracy and precision, robustness, and recovery from the both human plasma and urine. The recovery results clearly demonstrate the absence of endogenous matrix interference as the matrix effect is inferred if the ratio is $<85$ or $>115 \%$ [28].

\section{CONCLUSION}

A rapid, specific and sufficiently sensitive LCMS/MS method has been successfully developed and validated for the simultaneous quantification of the tyrosine kinase inhibitors TOF, CBZ, and AFB in human plasma and urine. The developed protocol allowed linear fitting of the analyte concentration with peak area ratio in the range of (1.0 - $100 \mathrm{ng} \mathrm{mL}^{-1}$ ) for all analytes. LLOQ values are 1.24, 0.91 and $1.05 \mathrm{ng} \mathrm{mL^{-1 }}$ for TOF, CBZ, and AFB, respectively. The developed method is simple and efficient and can be used in pharmacokinetics studies as well as in the monitoring of the investigated analytes in body fluids.

\section{DECLARATIONS}

\section{Acknowledgement}

The authors would like to extend their sincere appreciation to Deanship of Scientific Research at King Saud University for funding Research Group no. RG-1435-025.

\section{Conflict of Interest}

No conflict of interest associated with this work.

\section{Contribution of Authors}

The authors declare that this work was done by the authors named in this article and all liabilities pertaining to claims relating to the content of this article will be borne by them.

\section{Open Access}

This is an Open Access article that uses a funding model which does not charge readers or their institutions for access and distributed under the terms of the Creative Commons Attribution License (http://creativecommons.org/licenses/by 14.0) and the Budapest Open Access Initiative (http://www.budapestopenaccessinitiative.org/rea d), which permit unrestricted use, distribution, and reproduction in any medium, provided the original work is properly credited. 
Table 3: Intra- and inter-day accuracy and precision values of the proposed analytical procedure

\begin{tabular}{|c|c|c|c|c|c|c|c|c|c|c|c|c|c|c|c|c|c|c|}
\hline \multirow[t]{2}{*}{ Parameter } & \multicolumn{9}{|c|}{ Intra-day } & \multicolumn{9}{|c|}{ Inter-day } \\
\hline & \multicolumn{3}{|c|}{ TOF } & \multicolumn{3}{|c|}{$C B Z$} & \multicolumn{3}{|c|}{$A F B$} & \multicolumn{3}{|c|}{ TOF } & \multicolumn{3}{|c|}{$C B Z$} & \multicolumn{3}{|c|}{$A F B$} \\
\hline $\begin{array}{l}\text { Nominal } \\
\text { Conc. (ng } \\
\mathrm{mL}^{-1} \text { ) }\end{array}$ & 7.0 & 50 & 80 & 7.0 & 50 & 80 & 7.0 & 50 & 80 & 7.0 & 50 & 80 & 7.0 & 50 & 80 & 7.0 & 50 & 80 \\
\hline $\begin{array}{l}\text { Measured } \\
\text { Conc. (ng } \\
\mathrm{mL}^{-1} \text { ) }\end{array}$ & 6.95 & 49.85 & 80.01 & 6.98 & 49.98 & 79.95 & 6.97 & 50.14 & 80.98 & 6.92 & 49.08 & 78.89 & 6.92 & 49.17 & 78.78 & 6.90 & 48.85 & 78.95 \\
\hline $\begin{array}{l}\text { Accuracy } \\
(\mathrm{RE} \%)\end{array}$ & -0.71 & -0.31 & 0.07 & -0.27 & -0.04 & -0.06 & -0.41 & 0.29 & 1.22 & -1.20 & -1.85 & -1.38 & -1.08 & -1.66 & -1.52 & -1.41 & -2.3 & -1.32 \\
\hline $\begin{array}{l}\text { Precision } \\
\text { (CV\%) }\end{array}$ & 0.71 & 3.28 & 3.26 & 1.85 & 3.78 & 2.40 & 2.97 & 2.24 & 3.73 & 3.43 & 3.96 & 4.39 & 4.43 & 5.12 & 4.57 & 3.43 & 4.90 & 4.01 \\
\hline
\end{tabular}

Table 4: Results of the incurred sample reanalysis of the studied analytes in spiked human plasma $(n=3)$

\begin{tabular}{|c|c|c|c|c|c|c|c|c|c|}
\hline Parameter & \multicolumn{3}{|c|}{ TOF } & \multicolumn{3}{|c|}{ CBZ } & \multicolumn{3}{|c|}{ AFB } \\
\hline Nominal conc. $\left(\mathrm{ng} \mathrm{mL}^{-1}\right)$ & 10 & 50 & 100 & 10 & 50 & 100 & 10 & 50 & 100 \\
\hline $\begin{array}{l}\text { Mean initial measured } \\
\text { concentration }\left(\mathrm{ng} \mathrm{mL}^{-1}\right)\end{array}$ & 9.98 & 49.95 & 100.14 & 9.89 & 50.17 & 99.78 & 10.08 & 49.89 & 100.57 \\
\hline $\begin{array}{l}\text { Mean repeat measured } \\
\text { concentration }\left(\mathrm{ng} \mathrm{mL}^{-1}\right)\end{array}$ & 9.87 & 49.21 & 99.59 & 9.68 & 48.76 & 99.09 & 9.85 & 48.69 & 99.17 \\
\hline Difference (\%) & 1.18 & 1.48 & 0.55 & 2.18 & 2.85 & 0.69 & 2.32 & 2.45 & 1.39 \\
\hline
\end{tabular}

Table 5: Recovery data for the studied analytes in human plasma and urine

\begin{tabular}{|c|c|c|c|c|c|c|c|c|c|c|c|c|c|c|c|c|c|c|}
\hline \multirow{3}{*}{$\begin{array}{l}\text { Parameter } \\
\text { Nominal } \\
\text { conc. (ng } \\
\mathrm{mL}^{-1} \text { ) }\end{array}$} & \multicolumn{9}{|c|}{ Human plasma } & \multicolumn{9}{|c|}{ Human urine } \\
\hline & \multicolumn{3}{|c|}{ TOF } & \multicolumn{3}{|c|}{$C B Z$} & \multicolumn{3}{|c|}{$A F B$} & \multicolumn{3}{|c|}{ TOF } & \multicolumn{3}{|c|}{$C B Z$} & \multicolumn{3}{|c|}{$A F B$} \\
\hline & 7.0 & 50 & 80 & 7.0 & 50 & 80 & 7.0 & 50 & 80 & 7.0 & 50 & 80 & 7.0 & 50 & 80 & 7.0 & 50 & 80 \\
\hline $\begin{array}{l}\text { Recovery } \\
(\%)\end{array}$ & 98.44 & 97.92 & 98.74 & 98.87 & 99.78 & 99.83 & 98.14 & 99.56 & 98.89 & 99.81 & 100.03 & 99.80 & 100.21 & 100.25 & 98.69 & 99.39 & 98.38 & 99.73 \\
\hline $\begin{array}{l}\text { Precision } \\
\text { (\%RSD) }\end{array}$ & 3.11 & 2.59 & 2.76 & 3.89 & 3.93 & 2.97 & 1.72 & 3.52 & 3.26 & 2.23 & 3.18 & 2.48 & 2.99 & 2.83 & 2.76 & 2.59 & 4.18 & 2.57 \\
\hline $\begin{array}{l}\text { Absence of } \\
\text { matrix effect } \\
(\%)\end{array}$ & 98.46 & - & - & 96.29 & - & - & 97.79 & - & - & 97.70 & - & - & 96.85 & - & - & 95.42 & - & - \\
\hline
\end{tabular}


Table 6: Recovery of the analyzed TKIs in spiked human plasma as an indication of the method's robustness

\begin{tabular}{|c|c|c|c|}
\hline Parameter & Recovery fr & n spiked human & lasma ( \pm RSD\%) \\
\hline & TOF & CBZ & AFB \\
\hline $\begin{array}{l}\text { Optimum conditions* } \\
\text { Mobile phase composition (A:B v/v) }\end{array}$ & $98.37 \pm 2.82$ & $99.49 \pm 3.59$ & $98.86 \pm 2.83$ \\
\hline - $48: 52$ & $98.25 \pm 3.16$ & $98.79 \pm 2.84$ & - $\quad 99.15 \pm 2.71$ \\
\hline - $52: 48$ & - $\quad 97.98 \pm 2.75$ & $99.18 \pm 2.56$ & - $\quad 98.74 \pm 2.08$ \\
\hline$p H$ of solvent B & & & \\
\hline - 4.0 & - $\quad 97.25 \pm 2.89$ & - $\quad 98.47 \pm 2.84$ & - $\quad 98.58 \pm 3.10$ \\
\hline - 4.2 & - $\quad 98.08 \pm 3.28$ & - $\quad 98.84 \pm 2.37$ & - $\quad 97.98 \pm 2.81$ \\
\hline Flow rate $\left(\mathrm{mL} . \mathrm{min}^{-1}\right)$ & & & \\
\hline - $\quad 0.2$ & - $\quad 97.97 \pm 2.58$ & - $\quad 97.83 \pm 2.14$ & - $\quad 99.33 \pm 3.21$ \\
\hline - $\quad 0.4$ & $97.69 \pm 3.07$ & $98.47 \pm 2.52$ & $98.40 \pm 2.67$ \\
\hline
\end{tabular}

${ }^{*}$ Optimum conditions were given in the Experimental section

\section{REFERENCES}

1. Zhang J, Yang PL, Gray NS. Targeting cancer with small molecule kinase inhibitors. Nature Rev Cancer. 2009; 9: 28-39.

2. Arora A, Scholar EM. Role of Tyrosine Kinase Inhibitors in Cancer Therapy. J Pharmacol Expl Therapeut. 2005; 315: 971-979.

3. Walker JG, Ahern MJ, Coleman M, Weedon $H$, Papangelis V, Beroukas D, Roberts-Thomson PJ, Smith $M D$. Changes in synovial tissue Jak-STAT expression in rheumatoid arthritis in response to successful DMARD treatment. Annals of the Rheumatic Diseases. 2006; 65: 1558-1564.

4. O'Shea JJ, Holland SM, Staudt LM. JAKS and STATs in immunity, immunodeficiency, and cancer. New Engl J Medicin. 2013; 368: 161-170.

5. Solca F, Dahl G, Zoephel A, Bader G, Sanderson M, Klein C, Kraemer O, Himmelsbach F, Haaksma E, Adolf GR. Target binding properties and cellular activity of afatinib (BIBW 2992), an irreversible ErbB family blocker. J Pharmacol Expl Therapeut. 2012; 343: 342350.

6. U.S. Food and Drug Administration (FDA). Afatinib. In: Center for drug evaluation and Research, Ed. MD, USA, 12th July 2013.

7. Yakes FM, Chen J, Tan J, Yamaguchi K, Shi Y, Yu P, Qian F, Chu F, Bentzien F, Cancilla B. Cabozantinib (XL184), a novel MET and VEGFR2 inhibitor, simultaneously suppresses metastasis, angiogenesis, and tumor growth. Mol Cancer Therapeut 2011; 10: 2298-2308.

8. LaBranche TP, Jesson MI, Radi ZA, Storer CE, Guzova JA, Bonar SL, Thompson JM, Happa FA, Stewart ZS, Zhan $Y$. JAK inhibition with tofacitinib suppresses arthritic joint structural damage through decreased RANKL production. Arthritis Rheum. 2012; 64: 35313542.

9. Tofacitinib for treatment of rheumatoid arthritis (NDA 203214) [database on the Internet] 2012 [cited 20 Oct. 2015]. Available from: http://www.accessdata.fda.gov/drugsatfda_docs/rems/X eljanz_2015.06.19_REMS_full.pdf.
10. Fouad M, Helvenstein M, Blankert B. Ultra-High Performance Liquid Chromatography Method for the Determination of Two Recently FDA Approved TKIs in Human Plasma Using Diode Array Detection. J Anal Methods Chem. 2015; 2015: 6.

11. Stopfer $P$, Marzin $K$, Narjes $H$, Gansser D, Shahidi $M$, Uttereuther-Fischer $M$, Ebner $T$. Afatinib pharmacokinetics and metabolism after oral administration to healthy male volunteers. Cancer Chemother Pharmacol. 2012 Apr; 69: 1051-61.

12. Vejendla $R$, Subramanyam $C$, Veerabhadram G. New RP-HPLC Method For The Determination Of Afatinib Dimaleate In Bulk And Pharmaceutical Dosage Forms. Indo-American J Pharmaceut Res. 2015; 5: 2098-2111.

13. Zhong-li H, Gui-zhou H, Xiao-wei C. Determination of Afatinib Tablets by HPLC. Qilu Pharmaceut Affairs 204; 6: 337-338.

14. Xiang $S-X, W u^{*} H-L$, Kang $C$, Xie L-X, Yin $X-L, G u H-W$, $Y u R$-Q. Fast quantitative analysis of four tyrosine kinase inhibitors in different human plasma samples using three-way calibration- assisted liquid chromatography with diode array detection. J Separat Sci. 2015; 38: 2781-2788.

15. Wind S, Schmid M, Erhardt J, Goeldner R-G, Stopfer P. Pharmacokinetics of Afatinib, a Selective Irreversible ErbB Family Blocker, in Patients with Advanced Solid Tumours. Clin Pharmacokinet. 2013 2013/12/01; 52: 1101-1109.

16. Wu C, Xu X, Feng $C$, Shi Y, Liu W, Zhu X, Zhang J. Degradation kinetics study of cabozantinib by a novel stability-indicating LC method and identification of its major degradation products by LC/TOF-MS and LCMS/MS. J Pharm Biomed Anal. [Research Support, Non-U S Gov't]. 2014; 98: 356-63.

17. Wang $X$, Wang $S$, Lin $F$, Zhang $Q$, Chen $H$, Wang $X$, Wen C, Ma J, Hu L. Pharmacokinetics and tissue distribution model of cabozantinib in rat determined by UPLC-MS/MS. J Chromatogr B. 2015; 983-984: 125131.

18. SU Q, Li J, Ji X, Li J, Zhou T, Lu W, Li L. An LC-MS/MS method for the quantitation of cabozantinib in rat plasma: Application to a pharmacokinetic study. J Chromatogr B. 2015; 985: 119-123. 
19. Darwish HW, Abdelhameed AS, Bakheit AH, Alanazi AM. $A$ new method to determine the new $C$-Met inhibitor "Cabozantinib" in dosage form and human plasma via micelle-enhanced spectrofluorimetry. RSC Advances. 2015; 5: 40484-40490.

20. Gupta P, Chow V, Wang R, Kaplan I, Chan G, Alvey C, Ni G, Ndongo M-N, LaBadie RR, Krishnaswami $S$. Evaluation of the effect of fluconazole and ketoconazole on the pharmacokinetics of tofacitinib in healthy adult subjects. Clin. Pharmacol. Drug Dev. 2014; 3: 72-77.

21. Dhiman V, Giri KK, Sharma K, Zainuddin M, Mullangi R. Development and validation of a RP-HPLC method for the quantitation of tofacitinib in rat plasma and its application to a pharmacokinetic study. Biomed Chromatogr. 2015.

22. Wang N-N, Zhang D-L, Jiang X-H. Detection of Xeljanz Enantiomers in Diethyl Amine Active Pharmaceutical Ingredients and Tablets. Chirality. 2015; 27: 235-238.

23. Paniagua R, Campbell A, Changelian PS, Reitz BA, Prakash C, Borie DC. Quantitative analysis of the immunosuppressant CP-690,550 in whole blood by column-switching high-performance liquid chromatography and mass spectrometry detection. Therapeut Drug Monit. 2005; 27: 608-616.
24. Sharma K, Giri K, Dhiman V, Dixit A, Zainuddin $M$, Mullangi R. A validated LC-MS/MS assay for simultaneous quantification of methotrexate and tofacitinib in rat plasma: application to a pharmacokinetic study. Biomedical Chromatography. 2015; 29: 722-732.

25. Council for International Organizations of Medical Sciences. International ethical guidelines for biomedical research involving human subjects. Bulletin of Medical Ethics. Geneva, Switzerland: World Health Organization (WHO); 2002.

26. Almeida AMd, Castel-Branco MM, Falcao A. Linear regression for calibration lines revisited: weighting schemes for bioanalytical methods. J. Chromatogr. B: Anal. Technol. Biomed. Life Sci. 2002; 774: 215-222.

27. Durante C, Russo D, Verrienti A, Filetti S. XL184 (cabozantinib) for medullary thyroid carcinoma. Expert Opin Investig Drugs. 2011 2011/03/01; 20: 407-413.

28. Matuszewski BK, Constanzer ML, Chavez-Eng CM. Strategies for the Assessment of Matrix Effect in Quantitative Bioanalytical Methods Based on HPLC-MS/MS. Anal Chem. 2003 2003/07/01; 75: 30193030. 